Whybrow P, Moffatt S, Kay L, Thompson B, Aspray T, Duncan R. Assessing the need for arthritis training among paid carers in UK residential care homes: A focus group and interview study. Musculoskeletal Care 2017, 1-8.

\title{
Copyright:
}

Copyright (C) 2017 John Wiley \& Sons, Ltd. This is the peer reviewed version of the following article: Whybrow P, Moffatt S, Kay L, Thompson B, Aspray T, Duncan R. Assessing the need for arthritis training among paid carers in UK residential care homes: A focus group and interview study. Musculoskeletal Care $2017,1-8$, which has been published in final form at $10.1002 / \mathrm{msc} .1211$. This article may be used for noncommercial purposes in accordance with Wiley Terms and Conditions for Self-Archiving.

DOI link to article:

$\underline{10.1002 / \mathrm{msc} .1211}$

Date deposited:

$11 / 09 / 2017$

Embargo release date:

14 August 2018 


\section{Assessing the need for arthritis training amongst paid carers in UK residential care homes: a focus group and interview study}

\section{Paul Whybrow}

Affiliated address: Institute of Health and Society, Campus for Ageing and Vitality, Biomedical Research Building, Newcastle University, Newcastle upon Tyne NE4 5PL

Present address: School for Social and Community Medicine, Canynge Hall, 39 Whatley Road, Bristol BS8 2PS, United Kingdom,

Email: paul.whybrow@bristol.ac.uk

Tel: 01179287364

\section{Suzanne Moffatt}

Institute of Health and Society, Campus for Ageing and Vitality, Biomedical Research Building, Newcastle University, Newcastle upon Tyne NE4 5PL

Email: suzanne.moffatt@ncl.ac.uk

Tel: 01912085005 Fax: 01912081101

\section{Lesley Kay}

The Newcastle upon Tyne NHS Foundation Trust, Freeman Road, Newcastle Upon Tyne, NE7 7DN, UK

\section{Ben Thompson}

The Newcastle upon Tyne NHS Foundation Trust, Freeman Road, Newcastle Upon Tyne, NE7 7DN, UK

\section{Terry Aspray}

The Newcastle upon Tyne NHS Foundation Trust, Freeman Road, Newcastle Upon Tyne, NE7 7DN, UK

\section{Rachel Duncan (corresponding authoring)}

The Newcastle upon Tyne NHS Foundation Trust, Freeman Road, Newcastle Upon Tyne, NE7 7DN, UK

Email: $\underline{\text { r.duncan@ncl.ac.uk }}$

Tel: 01912085668 Fax: 01912081101 


\begin{abstract}
Objective

An educational and training needs assessment for arthritis care in residential homes.
\end{abstract}

Methods

Qualitative data were collected from three purposively selected residential homes: one independent, one in a regional chain and one in a national chain. Three researcher-led focus groups were conducted with paid carers $(\mathrm{N}=22)$ using vignette exercises; interviews were undertaken with 12 residents with joint pain ( $\mathrm{N}=12)$, five managerial staff, and two general practitioners. Data was compared and analysed thematically around care practices, communication and training.

Results

There is a lack of arthritis awareness among paid carers, although they regularly identify and manage arthritic symptoms. Residents rely on paid carers to recognise when pain and mobility problems are treatable. Senior staff and GPs rely on carers to identify arthritic problems. However, paid carers themselves undervalued the health significance of their activities and lacked the confidence to communicate important information to health care professionals. Few of the paid carers had received training in arthritis and many expressed a strong desire to learn about arthritis to improve their ability to provide better care.

\title{
Conclusions
}

Education for paid carers regarding arthritis is lacking and lags behind education about conditions such as dementia and diabetes. To fully meet the expectations of their care roles, paid carers require an awareness of what arthritis is and how to recognise symptoms. We suggest training should be aimed at improving confidence in communicating with colleagues, residents and health professionals with senior care staff receiving more in-depth training.

\section{Key words}

Arthritis, care homes, focus groups, joint pain, paid carers, qualitative research 
ARCH Manuscript (Musculoskeletal Care) 26 June 2017 


\section{Introduction}

In the United Kingdom (UK) the most rapidly growing section of the population is those aged over 80 years, and a substantial increase is expected in the number of older people requiring full-time and residential care (Jagger et al., 2011; Wittenberg et al., 2011). Against this background, the education of paid carers ${ }^{1}$ working in residential care homes has never been more important. The training and proficiency of paid carers can have a direct impact on the quality of life of residents (Baier et al., 2004; Manias, Gibson, \& Finch, 2011; Smith et al., 2016; Takai \& Uchida, 2009; Tse, Vong, \& Ho, 2012). Residents are dependent on the expertise of staff to meet what are increasingly complex and underestimated needs (Robbins, Gordon, Dyas, Logan, \& Gladman, 2013). Although training paid carers to properly and effectively care for older people is an 'ethical and policy imperative' (Rycroft-Malone et al., 2014), training in the UK is often inadequate (Robbins et al., 2013).

An estimated third of people over the age of 45 in England have sought treatment for osteoarthritis (Arthritis Research UK, 2009), which is associated with decreased activities of daily living (ADL), poor quality of life and chronic pain (Takai, Yamamoto-Mitani, Okamoto, Koyama, \& Honda, 2010; Zanocchi et al., 2008). In the United States a study estimated that only $19 \%$ of nursing home residents had any diagnosis of arthritis, and researchers suggest this low number is due to underreporting (Abell, Hootman, \& Helmick, 2004). It is suspected that joint problems and chronic pain are underreported generally in care homes (Abell et al., 2004; Baier et al., 2004; Smith et al., 2016; Tousignant-Laflamme et al., 2012). A study carried out by the British Geriatric Society expressed concerns that older people living in UK care homes have an inferior standard of care and inferior access to healthcare compared to peers living in the community (Martin, Thorpe, Heath, \& Noble, 2011). In the UK the residence-based experience of care in care homes does not live up to the standards of regulatory practice (Gladman \& Bowman, 2012).

\footnotetext{
${ }^{1}$ In this article 'paid carer' refers to care home staff who are employed to care for residents.
} 
"There is a pressing need for research that identifies interventions that can improve the skills and knowledge of the support workforce in order to promote safe, effective and responsive person-centred care to older people" (Rycroft-Malone, 2014: 1)

A recent systematic review of musculoskeletal disorders among care home residents suggests that assessment and pain management exercises can be effective in training staff to better meet residents' care needs (Smith et al., 2016). Other studies have found that educational intervention can reduce residents' chronic pain (Baier et al., 2004; Jones, Fink, Vojir, et al., 2004; Manias et al., 2011; Takai et al., 2010; Tse \& Ho, 2014). However, the issue is complex, requiring multifaceted interventions (Jones, Fink, Pepper, et al., 2004). Simply increasing paid carers' specific knowledge may not necessarily result in changes in practice or better care (Rycroft-Malone et al., 2014), so it is important to understand practice in order to inform realistic interventions. The aims of this study were to understand how residents' joint pain and mobility problems were managed, identify the education and training needs of paid carers, and to recommend methods to improve future curricula.

\section{Methods}

Qualitative methods were used to gain understanding of the meanings and practices related to arthritis care in care homes. In order to provide an organisational overview, we adopted a maximum variation sampling strategy (Merkens, 2004), conducting semi-structured interviews with managerial staff, general practitioners and residents with joint pain. We also conducted focus groups with care staff at each of the three homes.

Topic guides were developed following an examination of the relevant literature and discussion within a multidisciplinary study team of rheumatologists, a geriatrician, a social gerontologist and patient representatives. The topic guides were used as conversational prompts to encourage discussion around key topics. These included the organisation of staff training and organisation of arthritic care (senior staff), care home visits and treating residents' musculoskeletal problems (GPs), and discussing joint pain and immobility with care staff (residents). The semi structured approach enabled relevant topics to be 
covered, but had the flexibility to allow coverage of topics not anticipated by the research team. The interviews used a mix of open and closed questions; starting with open discussion before going into more detail. Interviews with residents tended to involve longer narratives, while the expert interviews were a more formal.

Qualitative research is understood as an interpretive process informed by ontological concerns without necessarily being restricted by them (Barbour, 2001; Seale, 1999). Our methodological approach can be described as a pragmatic in that it recognises the beliefs and practices of participants as having practical utility (Ormston, Spencer, Barnard, \& Snape, 2014). We understand paid care work from a sociological perspective as particular social roles that are contingent on discernible social structures, and reflexively engaged with by individuals.

\section{Recruitment and sampling}

The study was focused on residential care homes, which do not provide nursing care. Care homes were recruited from Newcastle and Northumbria with the help of ENRICH (Enabling Research in Care Homes) and included one independent home, one in a regional group and one in a national chain, as the available training and practices may differ between them. The independent home had 31 residents, all of whom were self-funded. The regional chain had 72 residents, $30 \%$ of whom were self-funded. The national chain had 60 residents, only $5 \%$ of whom were self-funded. Most residents in the private and regional homes had dementia compared to approximately half of the residents in the national chain. Care home managers coordinated the recruitment of paid carers and residents with joint pain, with a questionnaire which we then used to purposively sample. Senior residential home staff and managers were approached individually. Approval was obtained from the Social Care Research Ethics Committee (reference: 14/IEC08/1007). Written consent was obtained from all participants. Residents with cognitive impairment were included but had to have capacity to consent. 


\section{Data collection and analysis}

The focus groups and resident interviews were undertaken within the care home, lasted no more than 60 minutes and were digitally recorded. Senior staff interviews took place at their place of work. Focus groups and interviews were conducted by PW, RD and SM, none of whom had direct care for any residents involved. Focus groups were undertaken with paid carers and facilitated by three thematic vignettes to prompt open discussion (see Box 1). Participants in all three focus groups reported that these scenarios were recognisable.

Recordings were transcribed verbatim and anonymised. Transcripts were read and checked by PW, RD and SM. A coding framework was developed alongside data-collection and modified as new themes emerged until a final coding framework was derived. Coding was open and conducted transcript by transcript, reiteratively refining key themes. Two transcripts were double coded to check for inter-coder reliability (Campbell, Quincy, Osserman, \& Pedersen, 2013). Qualitative Data Analysis (QDA) software was used to support data management and retrieval (Weitzman, 1999). The coding and analysed following the principles of thematic analysis (Braun \& Clarke, 2006). Thematic analysis provided an interpretive way of exploring and comparing beliefs, narratives, and roles of different groups. The key themes that emerged from the data are presented in this article: routines of care, roles and responsibilities, communication and arthritis knowledge/training.

\section{Results}

Table 1 shows the characteristics of the focus group participants and table 2 outlines the characteristics of the residents interviewed. Data from focus groups and interviews are presented together, according to the key themes identified: Care practices, Senior staff and delegation, Communication and healthcare professionals, Identifying joint pain and mobility problems, Residents' expectations of care and Arthritis awareness and training. 


\section{Care practices}

Analysis shows how managing joint pain and mobility problems happened informally through routine activities of daily living (ADL). In each of the three homes care practices were routinized and focused on ADLs, such as meals, toileting, bathing and bedtime. Through these, carers were implicitly responsible for monitoring residents' health and wellbeing.

"We do have to do quite a lot of housekeeping as our daily ritual: make beds, tidy rooms, put laundry, we do washing. [...] And if somebody wasn't well like, we would make time. We would find out what was wrong. We would find out pretty quickly, you know, and try and establish what the problem was, and then, and deal with it."

(Paid carer, FG 1)

"Getting them up for the toilet and putting 'em back and sort of seeing what they're like, you know?"

(Paid carer, FG 1)

However, these activities were not acknowledged as arthritis care. Paid carers reported that residents had 'aches and pains,' but were not able to say if any had arthritis. One care home manager said the only residents with arthritis were those diagnosed before arriving at the home and that a current resident would rarely be diagnosed.

"I don't think, within my home, I don't have that many with arthritis - I mean, yes, achy bones, and you know." (Senior staff 1, interview)

GPs reported that, although they often came across residents with musculoskeletal problems, this was rarely the reason for being called in.

"They're people who are very frail, often with multiple morbidities, so you know the input is quite massive for that particular population. I would say joint pain's not - well it certainly is cause for visiting - but it's probably not the commonest cause." (GP 1, interview)

Arthritis has a relatively low priority alongside multiple and complex health needs. 
Senior staff and delegation

In each home there were clear procedures for escalating care for residents identified as having problems. When paid carers suspected a problem they described discussing it with their peers before deciding whether to alert a senior staff member. If there was a formal process it could be summarised as: if in doubt, ask the senior.

"The carers wouldn't make that decision. If they had any concerns they would pass onto the senior." (Senior staff 2, interview)

"I mean, just an ordinary carer [Yeah] wouldn't, would be no point in asking, I don't think they're capable of, you know, dealing with it [Yeah], it would have to be a senior, that." (Paid carer, FG 3)

The senior staff member would decide whether to inform the manager or a healthcare professional. Within each of the three homes this process of delegation was key to joint pain management.

\section{Communication and healthcare professionals}

Paid carers expressed different attitudes towards healthcare professionals. Although some had had positive experiences, others felt undervalued by healthcare professionals.

"I think qualified staff think because they've actually got a recognised qualification and that, that they're recognised as having a vocation, we're sort of the, the poor relations." (Paid carer, FG 2)

Some carers described moments of victory when they had succeeded in helping a resident where the healthcare professionals had failed.

"It's an achievement, because well, you know, the professionals couldn't do what we did! 'Cause there does tend to be a lot of snobbery between qualified and care staff" (Paid carer, FG 1) 
Such successes came from knowing the residents and recognising changes in behaviour. Unfortunately, few paid carers were confident enough to share what they knew and thought it more appropriate to delegate. For example, this carer describes a possible interaction with a GP.

"[Carers] don't have any knowledge, they can't actually make a suggestion! Sometimes the GP will say, 'Well, what do you think? What do you think I should give them?' You'll say, 'Well, I can't!' It's like, 'Well, you're the doctor, it's up to you!' And, you know, sometimes we know the residents better and what we think would work!" (Senior staff 3, interview)

Other accounts of such interactions reveal anxiety about discussing any aspect of residents' health with healthcare professionals. Paid carers said it was 'not their place' to give an opinion or were worried about giving 'incorrect' information.

"It's just so that you don't give the wrong information. I could get summat wrong and then I might get summat diagnosed wrong or I might get it wrong, mightn't I? If I give the wrong information?" (Paid carer, FG 3)

"You've got to be careful not to give an opinion. You're not qualified so you can't give an opinion." (Paid carer, FG 2)

This reluctance was particularly evident in the responses to the third scenario exercise, in which paid carer 'Laura' does not speak with GPs (Box 1). One group sympathised and defended Laura's silence, saying that it was inappropriate for her to express an opinion. In another group, the carers agreed she should keep silent if she had not had formal training.

"She's not offering her opinion 'cause the doctor's there." (Paid caregiver, FG 3)

"She maybe just doesn't feel that she's trained in that field." (Paid caregiver, FG 3)

The caution and reluctance to volunteer information to healthcare professionals was common among carers, and relates to notions of boundaries of care responsibility and underestimating the health value of carers' knowledge. 
Identifying joint pain and mobility problems

Across the focus groups, paid carers were clear in saying that they would not expect residents to be forthcoming about joint pain. They recognised it as their responsibility to identify when something was wrong, and described looking for subtle clues.

"Body language and facial expressions, or they could be withdrawn. You know, there's loads of different ways that you can tell that someone is not themselves. And because we know the residents really well, working with them every day, we know when there's something not right." (Paid carer, FG 1)

Accounts of successfully identifying residents' pain and immobility were interrelated with having an intimate knowledge of residents, their personalities and habits. This unique perspective was also valued by senior staff, managers and the GPs.

"It's the carers who know, they spot the changes: they see when things are going wrong. But I get the impression they don't always feel that they have the right to say so. [...] They're there 24 hours a day. They watch these patients and they have all the information... You ask the nurses and they haven't got a clue, it's the carers who are there all the time, you know." (GP 2, interview)

Residents' expectations of care Residents tolerated and normalised their pain and immobility to a considerable degree and described pains they did not volunteer to paid care staff.

"I'm 96, so there's not much anybody can do." (Resident 3, interview) "I wouldn't be surprised [if I had undiagnosed arthritis]. Yes. I don't be surprised. Old age as well." (Resident interview) 
Residents, who often spoke fondly of carers as a 'second family,' trusted carers to distinguishing their 'aches and pains' from treatable conditions requiring intervention. Residents described tolerating pain and assuming it was not a cause for concern unless identified as such by a carer.

"They're [legs] hurting every day! [Laughs] But there's nothing they [paid carers] can do, I don't think." (Resident 9, interview)

These accounts from residents make sense in the context of a community in which aches and pains are commonplace. As older people can be unaware of what is normal in being and becoming older (Sanders, Donovan, \& Dieppe, 2002), paid carers are perceived as experts in their own (ageing) health. When asked whether she wanted pain relief for her painfully stiff hand, a resident was surprised and replied it was not her place to say.

"Well, I don't know if I'd be able to take any. I don't know. I don't know. I would have to have a doctor to tell me what I can do. It's not for me to say. For a doctor that knows my circumstances as it were. A medical-mm... Anyway, I can, you see, [shows other hand] I have got use of this hand so that's good." (Resident 5, interview)

Another resident describes how inappropriate it would be for her to tell care staff that she should receive pain relief for her aching joints.

"You cannot - I'm just a resident! - I cannot turn around and tell them, you know, 'Well you should...' and ask for something like that [I: Yeah] 'You should do this or that!' That's, it's not my business really."

(Resident 7, interview)

These responses illustrate how residents felt that their health is the business and responsibility of paid carers. This makes it all the more important that carers are able to identify arthritic problems. 
Arthritis awareness and training

During the focus groups, none of the paid carers could describe having any formal training in arthritis care $^{2}$. They reported little understanding of what arthritis is or how it should be managed or treated.

"We're really big on training, this is what I'm saying: I can't understand how arthritis has never been brought up!" (Paid carer, FG 3)

"I think that's where there's a lack of training for people, you know, somebody that's new to care who maybe hasn't experienced arthritis and symptoms, and I think there should be some form of training devised so that people can be taught what to look for and how to deal with it." (Paid carer, FG 1)

In fact, some of the carers admitted they had only agreed to participate in the study because they hoped to learn about arthritis. Carers were keen to better understand arthritis to improve care provision. They felt a strong personal duty to look after residents; their desire to learn was related to anxiety that they might be missing something or getting something wrong.

"Obviously we know the patients, but we could still be doing something wrong or there could be a better way of doing it or more exercises we could be doing, which could help ease their pain and help their mobility [collective agreement]." (Paid carer, FG 1)

This anxiety is illustrated in this account of deciding not to provide light keep fit classes. Educational intervention could focus on elevating these anxieties.

"I used to do general exercises with them, their feet, their knees, lifting their shoulders, their hands. Until I was actually told that I could actually fracture somebody's joints by making them do [it]. I says, 'Well I'm not doing it, I'm only asking them to...' So then because it was a risk I stopped doing it." (Paid carer, FG 2)

\footnotetext{
${ }^{2}$ Although two of the participants reporting having had arthritis training in the questionnaires (Table 1). The difference may reflect informal 'on-the-job' rather than formal training.
} 
Paid carers expressed a preference for practical, 'hands on' training and content that related directly to their daily care work.

"To get an understanding of what the residents are going through and how you can help them, like, manage it better." (Paid carer, FG 3)

A little bit of, you know, an exercise so you are actually, you are doing different activities. (Senior staff)

Face-to-face learning, either from a visiting trainer or from one another, was also regarded as preferable to online training.

\section{Discussion}

As the population ages, residential homes are likely to become more important as a point of intervention for the care of older people (Gladman \& Bowman, 2012). Previous research has found an urgent need for training interventions aimed at support workers for older people (Rycroft-Malone et al., 2014). Our findings add further evidence that improved training can benefit both care home residents and paid carers (Abell et al., 2004).

A key finding of this study is that the activities of paid carers are unavoidably connected to residents' health. To many older people, joint pain is experienced as disruption, yet normalised as part of the renewed biography of being and becoming older (Sanders et al., 2002), which explains why many older people tolerate arthritic pain and stiffness as 'normal aches and pains' (Sheppard, Kumar, Buckley, Shaw, \& Raza, 2008). Therefore, the responsibility to identify and monitor residents' joint pain and mobility problems often lies with paid carers who are, and should be, the frontline of arthritis care in care homes. Paid carers are passionate about providing good care and welcomed opportunities to learn. However, they had little knowledge of arthritis, despite its relevant to their practices. They could not describe any previous arthritis care training, despite having received training for other conditions such as such as diabetes and dementia. 
One suggestion for improving arthritis care is to make roles and responsibilities for dealing with joint pain more explicit (Robbins et al., 2013). We found that joint pain is typically managed through processes of delegation: paid carers are responsible for recognising issues and alerting senior staff who decide whether a healthcare professional is needed. However, uncertainty and anxiety was apparent among paid carers and senior staff about how and when to seek further help for joint pain and mobility problems. Professional divisions between paid carers and healthcare professionals undermine carers' confidence in communicating important information about residents. Training should emphasize the value of carers' knowledge of residents and improve their confidence in communicating this to healthcare professionals. Previous studies have suggested improving carers' capacity to communicate with residents (Burgio et al., 2001). However, it may be just as important that carers are able to communicate with colleagues and health professionals. In itself, training may be ineffective if not targeted and embedded in actual practice (Nolan et al., 2008). We found that paid carers preferred hands-on, practical learning. How training would fit with a higher staff turnover should be considered and may be more achievable for senior staff.

The strength of this study is in combining multiple perspectives and in-depth qualitative analysis to better understand how joint pain and mobility problems are managed in care homes. The congruence of accounts amongst participants from independent, regional and national care homes supports the transferability of the findings to other settings (Ritchie, Lewis, Nicholls, \& Ormston, 2013), although further work in a wider range of care settings is still required. A limitation of this study is that data was collected from only three care homes. Additionally, the study did not involve paid carers for whom English was a second language.

\section{Conclusion}

Care home residents tend to tolerate joint pain and depend on care staff to recognise when pain and immobility require intervention. Fulfilling these responsibilities requires improving carers' competence in identifying arthritic problems and confidence in communicating important information to senior staff 
and healthcare professionals. We recommend two models of training: (i) arthritis awareness for paid carers and (ii) a detailed training package for senior carers. Research is now required to develop packages that are acceptable and deliverable to the care home community.

\section{Acknowledgements}

We would like to thank all the participants involved in the study and the patient and public representative. Additionally, thanks to Victoria Morgan for providing administrative support to this project.

\section{Funding}

This work was supported by the JGW Patterson Foundation (Ref: 30015.088.027/ - 16 of 2013)

\section{Conflicts of interest}

The authors declare no conflict of interest. 
Box 1: Vignettes used to facilitate discussion with the paid carer focus groups

\section{Vignette 1: resident exhibiting signs of joint pain}

Joyce is 85 and has recently joined the care home. She is very talkative and likeable and fits in well with the other residents. She spends most of the afternoon sitting in a chair in the living room. You have noticed that she seems to be in pain as she tries to get up. When you ask, Joyce says that everything is fine. You think she is struggling to move because of pain in her knees.

\section{Vignette 2: resident whose behaviour changed because of joint pain}

Martin is 85 and has been at the home for five years. He is having some difficulty hearing and can be quite quiet and forgetful. Martin is suffering from joint pain in his arms and hands. However, he enjoys being with other residents and is always up early for breakfast. Yesterday Martin stayed in bed all morning and missed breakfast and you think it is because of his joint pain.

\section{Vignette 3: paid carer who lacks confidence in communicating with healthcare professionals}

Laura has been working as a carer for eight years at the same home. She previously worked as a cleaner and did not get any formal care training until recently when she did an NVQ Level 2. Having worked at the home for eight years, she now feels that she knows the residents well. Laura is sensitive, caring and well-liked by the residents and staff. You have noticed that she becomes very quiet when a GP visits, and doesn't offer her opinions. Laura knows a lot about the residents that could be helpful to the GP. 


\begin{tabular}{|c|c|c|c|c|}
\hline & All & Independent & Regional & National \\
\hline No. in focus group & 22 & 8 & 9 & 5 \\
\hline $\begin{array}{l}\text { Job role } \\
\text { Carer } \\
\text { Senior carer }\end{array}$ & $\begin{array}{l}15 \\
7\end{array}$ & $\begin{array}{l}4 \\
4\end{array}$ & $\begin{array}{l}7 \\
2\end{array}$ & $\begin{array}{l}4 \\
1\end{array}$ \\
\hline $\begin{array}{l}\text { Age: } \\
\text { Mean } \\
\text { Median } \\
\text { range }\end{array}$ & $\begin{array}{l}49.5 \\
55 \\
20-65\end{array}$ & $\begin{array}{l}52.6 \\
56 \\
28-65\end{array}$ & $\begin{array}{l}50.8 \\
56 \\
34-61\end{array}$ & $\begin{array}{l}42 \\
42 \\
20-58\end{array}$ \\
\hline $\begin{array}{l}\text { Gender } \\
\text { Female } \\
\text { male }\end{array}$ & $\begin{array}{l}21 \text { (96\%) } \\
1\end{array}$ & $\begin{array}{l}8(100 \%) \\
-\end{array}$ & $\begin{array}{l}9(100 \%) \\
-\end{array}$ & $\begin{array}{l}4(80 \%) \\
1\end{array}$ \\
\hline $\begin{array}{l}\text { Length of time as carer } \\
\text { Mean } \\
\text { Median } \\
\text { range }\end{array}$ & $\begin{array}{l}14.7 \\
11.5 \\
0.5-40\end{array}$ & $\begin{array}{l}22.4 \\
23 \\
10-24\end{array}$ & $\begin{array}{l}12.1 \\
6.8 \\
3.5-40\end{array}$ & $\begin{array}{l}7.1 \\
1.2 \\
0.5-25\end{array}$ \\
\hline $\begin{array}{l}\text { Length of time at current } \\
\text { care home } \\
\text { Mean } \\
\text { Median } \\
\text { range }\end{array}$ & $\begin{array}{l}7.0 \\
3.5 \\
0.3-30\end{array}$ & $\begin{array}{l}13.8 \\
14 \\
0.6-30\end{array}$ & $\begin{array}{l}2.2 \\
2.1 \\
0.3-4.2\end{array}$ & $\begin{array}{l}4.6 \\
1.2 \\
0.5-14\end{array}$ \\
\hline $\begin{array}{l}\text { Formal qualifications } \\
\text { No } \\
\text { NVQ } 2 \\
\text { NVQ } 3 \\
\text { NVQ } 4\end{array}$ & $\begin{array}{l}5(23 \%) \\
7 \\
8 \\
2\end{array}$ & $\begin{array}{l}1(12.5 \%) \\
3 \\
4 \\
-\end{array}$ & $\begin{array}{l}1(11.1 \%) \\
3 \\
3 \\
2\end{array}$ & $\begin{array}{l}3(60 \%) \\
1 \\
1 \\
-\end{array}$ \\
\hline $\begin{array}{l}\text { Arthritis/joint pain training } \\
\text { Yes } \\
\text { No } \\
\text { Missing data }\end{array}$ & $\begin{array}{l}2 \\
19(86 \%) \\
1\end{array}$ & $\begin{array}{l}2 \\
5(63 \%) \\
1\end{array}$ & $\begin{array}{l}- \\
9(100 \%) \\
-\end{array}$ & $\begin{array}{l}- \\
5(100 \%) \\
-\end{array}$ \\
\hline
\end{tabular}


Table 2: Demographics of residents participating in the interviews

\begin{tabular}{|c|c|c|c|c|}
\hline & All & Independent & Regional & National \\
\hline No. of residents interviewed & 12 & 4 & 4 & 4 \\
\hline $\begin{array}{c}\text { Gender } \\
\text { Female } \\
\text { Male } \\
\end{array}$ & $\begin{array}{l}12 \\
- \\
\end{array}$ & $\begin{array}{l}4 \\
- \\
\end{array}$ & $\begin{array}{l}4 \\
- \\
\end{array}$ & $\begin{array}{l}4 \\
- \\
\end{array}$ \\
\hline $\begin{array}{l}\text { Age } \\
\text { Mean } \\
\text { Median } \\
\text { Range } \\
\end{array}$ & $\begin{array}{l}90.3 \\
90 \\
81-97 \\
\end{array}$ & $\begin{array}{l}88,87,90,96 \\
90.3 \\
89 \\
87-96 \\
\end{array}$ & $\begin{array}{l}81,94,94,95 \\
91 \\
94 \\
81-95 \\
\end{array}$ & $\begin{array}{l}84,90,97,88 \\
89.8 \\
89 \\
84-97 \\
\end{array}$ \\
\hline $\begin{array}{l}\text { Duration at current home } \\
\text { (years) } \\
\text { Mean } \\
\text { Median } \\
\text { Range }\end{array}$ & $\begin{array}{l}4.2 \\
1.5 \\
0.66-26\end{array}$ & $\begin{array}{l}8.4 \\
3.2 \\
1.1-26\end{array}$ & $\begin{array}{l}1.4 \\
1.0 \\
0.6-2\end{array}$ & $\begin{array}{l}2.8 \\
4.6 \\
0.5-8\end{array}$ \\
\hline $\begin{array}{l}\text { Severity of joint pain } \\
\text { Mild } \\
\text { Moderate } \\
\text { Severe }\end{array}$ & $\begin{array}{l}4 \\
5 \\
3 \\
\end{array}$ & $\begin{array}{l}1 \\
2 \\
1 \\
\end{array}$ & $\begin{array}{r}2 \\
2 \\
- \\
\end{array}$ & $\begin{array}{l}1 \\
1 \\
2 \\
\end{array}$ \\
\hline $\begin{array}{l}\text { Level of independence } \\
\text { Fully independent } \\
\text { Requires some assistance } \\
\text { Requires a lot of assistance } \\
\text { Completely dependent }\end{array}$ & $\begin{array}{l}- \\
7 \\
3 \\
2\end{array}$ & $\begin{array}{l}- \\
1 \\
2 \\
1\end{array}$ & $\begin{array}{l}- \\
3 \\
- \\
1\end{array}$ & $\begin{array}{l}- \\
3 \\
1 \\
-\end{array}$ \\
\hline
\end{tabular}




\section{References}

Abell, J., Hootman, J., \& Helmick, C. (2004). Prevalence and impact of arthritis among nursing home residents. Annals of the Rheumatic Diseases, 63(5), 591-594. doi:http://dx.doi.org/10.1136/ard.2003.015479

Arthritis Research UK. (2009). Osteoarthritis in General Practice: Data and Perspectives. Retrieved from http://www.arthritisresearchuk.org/policy-and-public-affairs/reportsand-resources/reports.aspx

Baier, R. R., Gifford, D. R., Patry, G., Banks, S. M., Rochon, T., DeSilva, D., \& Teno, J. M. (2004). Ameliorating pain in nursing homes: a collaborative quality-improvement project. Journal of the American Geriatrics Society, 52(12), 1988-1995. doi:10.1111/j.15325415.2004.52553.x

Barbour, R. S. (2001). Checklists for improving rigour in qualitative research: a case of the tail wagging the dog? BMJ, 322. doi:10.1136/bmj.322.7294.1115

Braun, V., \& Clarke, V. (2006). Using thematic analysis in psychology. Qual Res Psychol, 3. doi:10.1191/1478088706qp063oa

Burgio, L. D., Allen-Burge, R., Roth, D. L., Bourgeois, M. S., Dijkstra, K., Gerstle, J., . . Bankester, L. (2001). Come talk with me improving communication between nursing assistants and nursing home residents during care routines. The Gerontologist, 41(4), 449-460. doi:https://doi.org/10.1093/geront/41.4.449

Campbell, J. L., Quincy, C., Osserman, J., \& Pedersen, O. K. (2013). Coding in-depth semistructured interviews: Problems of unitization and intercoder reliability and agreement. Sociological Methods \& Research, 42(3), 294-320. doi:https://doi.org/10.1177/0049124113500475

Gladman, J. R., \& Bowman, C. E. (2012). Quality of care and the quality of life in care homes. Age and Ageing, 41(4), 426-427. doi:https://doi.org/10.1093/ageing/afs080

Jagger, C., Collerton, J. C., Davies, K., Kingston, A., Robinson, L. A., Eccles, M. P., . . Kirkwood, T. B. (2011). Capability and dependency in the Newcastle 85+ cohort study. Projections of future care needs. BMC Geriatrics, 11(1), 21. doi:10.1186/1471-2318-11-21

Jones, K. R., Fink, R., Pepper, G., Hutt, E., Vojir, C. P., Scott, J., . . Mellis, K. (2004). Improving nursing home staff knowledge and attitudes about pain. The Gerontologist, 44(4), 469478. doi:https://doi.org/10.1093/geront/44.4.469

Jones, K. R., Fink, R., Vojir, C., Pepper, G., Hutt, E., Clark, L., . . Mellis, B. K. (2004). Translation Research in Long-Term Care: Improving Pain Management in Nursing Homes. Worldviews on Evidence-Based Nursing, 1(s1), S13-S20. doi:10.1111/j.1524475X.2004.04045.X

Manias, E., Gibson, S. J., \& Finch, S. (2011). Testing an educational nursing intervention for pain assessment and management in older people. Pain Medicine, 12(8), 1199-1215. doi:10.1111/j.1526-4637.2011.01181.x

Martin, F., Thorpe, T., Heath, H., \& Noble, H. (2011). Quest for Quality: An Inquiry Into the Quality of Healthcare Support for Older People in Care Homes: A Call for Leadership, Partnership and Improvement. London: British Geriatrics Society. 
Merkens, H. (2004). Selection Procedures, Sampling, Case Construction. In U. Flick, E. v. Kardoff, \& I. Steinke (Eds.), A Companion to Qualitative Research (pp. 165-177). London: Sage.

Nolan, M., Davies, S., Brown, J., Wilkinson, A., Warnes, T., McKee, K., . . Stasi, K. (2008). The role of education and training in achieving change in care homes: a literature review. Journal of Research in Nursing, 13(5), 411-433. doi:https://doi.org/10.1177/1744987108095162

Ormston, R., Spencer, L., Barnard, M., \& Snape, D. (2014). The foundations of qualitative research. Qualitative Research Practice: A Guide for Social Science Students and Researchers, 1-25.

Ritchie, J., Lewis, J., Nicholls, C. M., \& Ormston, R. (2013). Qualitative Research Practice: A Guide for Social Science Students and Researchers: Sage.

Robbins, I., Gordon, A., Dyas, J., Logan, P., \& Gladman, J. (2013). Explaining the barriers to and tensions in delivering effective healthcare in UK care homes: a qualitative study. $B M J$ Open, 3(7), e003178. doi:http://dx.doi.org/10.1136/bmjopen-2013-003178

Rycroft-Malone, J., Burton, C., Hall, B., McCormack, B., Nutley, S., Seddon, D., \& Williams, L. (2014). Improving skills and care standards in the support workforce for older people: a realist review. BMJ Open, 4(5), e005356. doi:http://dx.doi.org/10.1136/bmjopen2014-005356

Sanders, C., Donovan, J., \& Dieppe, P. (2002). The significance and consequences of having painful and disabled joints in older age: co-existing accounts of normal and disrupted biographies. Sociology of Health and IIIness, 24(2), 227-253. doi:10.1111/14679566.00292

Seale, C. (1999). Quality in qualitative research. Qualitative inquiry, 5(4), 465-478.

Sheppard, J., Kumar, K., Buckley, C. D., Shaw, K. L., \& Raza, K. (2008). 'I just thought it was normal aches and pains': a qualitative study of decision-making processes in patients with early rheumatoid arthritis. Rheumatology, 47(10), 1577-1582. doi:https://doi.org/10.1093/rheumatology/ken304

Smith, T. O., Purdy, R., Latham, S. K., Kingsbury, S. R., Mulley, G., \& Conaghan, P. G. (2016). The prevalence, impact and management of musculoskeletal disorders in older people living in care homes: a systematic review. Rheumatology International, 36(1), 55-64. doi:10.1007/s00296-015-3322-1

Takai, Y., \& Uchida, Y. (2009). Frequency and type of chronic pain care approaches used for elderly residents in Japan and the factors influencing these approaches. Japan Journal of Nursing Science, 6(2), 111-122. doi:10.1111/j.1742-7924.2009.00129.x

Takai, Y., Yamamoto-Mitani, N., Okamoto, Y., Koyama, K., \& Honda, A. (2010). Literature review of pain prevalence among older residents of nursing homes. Pain Management Nursing, 11(4), 209-223. doi:https://doi.org/10.1016/i.pmn.2010.08.006

Tousignant-Laflamme, Y., Tousignant, M., Lussier, D., Lebel, P., Savoie, M., Lalonde, L., \& Choinière, M. (2012). Educational needs of health care providers working in long-term care facilities with regard to pain management. Pain Research and Management, 17(5), 341-346. doi:http://dx.doi.org/10.1155/2012/506352 
Tse, M. M. Y., \& Ho, S. S. (2014). Enhancing knowledge and attitudes in pain management: A pain management education program for nursing home staff. Pain Management Nursing, 15(1), 2-11. doi:https://doi.org/10.1016/j.pmn.2012.03.009

Tse, M. M. Y., Vong, S. K. S., \& Ho, S. S. (2012). The effectiveness of an integrated pain management program for older persons and staff in nursing homes. Archives of Gerontology and Geriatrics, 54(2), e203-e212. doi:https://doi.org/10.1016/i.archger.2011.04.015

Weitzman, E. A. (1999). Analyzing qualitative data with computer software. Health Services Research, 34(5 Pt 2), 1241.

Wittenberg, R., Hu, B., Hancock, R., Morciano, M., Comas-Herrera, A., Malley, J., \& King, D. (2011). Projections of demand for and costs of social care for older people in England, 2010 to 2030 under current and alternative funding systems. Retrieved from http://eprints.Ise.ac.uk/40720/

Zanocchi, M., Maero, B., Nicola, E., Martinelli, E., Luppino, A., Gonella, M., . . Obialero, R. (2008). Chronic pain in a sample of nursing home residents: prevalence, characteristics, influence on quality of life (QoL). Archives of Gerontology and Geriatrics, 47(1), 121-128. doi:https://doi.org/10.1016/i.archger.2007.07.003 